Ziad Darkhabani, MD

Thanh Nguyen, MD

Marc A. Lazzaro, MD

Osama O. Zaidat, MD

John R. Lynch, MD

Brian-Fred Fitzsimmons,

MD

Italo Linfante, MD,

FAHA

Correspondence \& reprint

requests to Dr. Linfante:

italol@baptisthealth.net

\section{Complications of endovascular therapy for acute ischemic stroke and proposed management approach}

\section{ABSTRACT}

Over the past decade, endovascular therapy has emerged as a promising therapeutic approach for select patients with acute ischemic stroke. However, the morbidity, mortality, and complication rates in intra-arterial recanalization trials are higher than in the National Institute of Neurological Disorders and Stroke trial of IV tissue plasminogen activator. This review discusses common complications associated with endovascular therapy for acute ischemic stroke, avoidance of complications, and management of some of the common complications. Neurology ${ }^{\circledR} 2012 ; 79$ (Suppl 1):S192-S198

\section{GLOSSARY}

AIS = acute ischemic stroke; IA = intra-arterial; NINDS = National Institute of Neurological Disorders and Stroke; $\mathbf{t P A}=$ tissue plasminogen activator.

Stroke remains the third leading cause of death in developed countries and the most common cause of permanent disability. ${ }^{1}$ Recanalization of the occluded cerebral vessel has been shown to be one of the strongest predictors of good outcome in endovascular therapy for acute ischemic stroke (AIS). ${ }^{2}$ Therefore, the goal of AIS treatment is to restore cerebral blood flow as rapidly and safely as possible. ${ }^{3}$

The US Food and Drug Administration approval for IV tissue plasminogen activator (tPA) thrombolysis in 1996 changed the landscape and management of AIS over the past 15 years. ${ }^{4}$ However, the strict inclusion criteria for IV tPA treatment limits its use to only a small proportion of AIS patients. In addition, it has been shown that IV tPA results in low recanalization rates or reocclusion after reperfusion in large-vessel occlusions. ${ }^{5}$ Over the past decade, endovascular therapy has emerged as a promising therapeutic approach for select patients with AIS. However, the morbidity, mortality, and complication rates in intra-arterial (IA) recanalization trials are higher than in the National Institute of Neurological Disorders and Stroke (NINDS) IV tPA trial (table 1). Although the comparison between the 2 therapies is not entirely accurate, given the different patient populations (different time windows, type of ischemic stroke, and mean NIH Stroke Scale score), the complication rates remain high and multiple strategies have been proposed for prevention and management of these complications.

This review discusses common complications associated with AIS endovascular therapy, avoidance of complications, patient selection criteria, and management of some of the common complications.

COMPLICATIONS ASSOCIATED WITH AIS ENDOVASCULAR THERAPY Complications associated with AIS endovascular intervention can be divided into 5 main categories (table 2): complications related to arterial access, medication and contrast media complications, systemic complications, anesthesia-related complications, and device-related complications.

Periprocedural hemorrhage is the most frequent complication and is usually associated with the use of antithrombotic and thrombolytic agents.

From the Departments of Neurology, Neurosurgery, and Radiology (Z.D., M.A.L., O.O.Z., J.R.L., B.F.F.), Medical College of Wisconsin, Milwaukee; Department of Neurology (T.N.), Boston Medical Center, Boston, MA; and Endovascular Surgical Neuroradiology Program (I.L.), Baptist Cardiac and Vascular Institute, Miami, FL.

Go to Neurology.org for full disclosures. Disclosures deemed relevant by the authors, if any, are provided at the end of this article. 
Table 1 The rate of the most common complications in some of the major stroke trials

\begin{tabular}{lllllll} 
& \multicolumn{2}{l}{ Complication, \% of patients } & & \\
\cline { 3 - 5 } Trial & Investigation & AICH & sICH & ARF & Groin hematoma & Mortality, \% \\
NINDS & IV tPA & - & 6.4 & - & - & 17 \\
PROACT I & IA pro-UK & 27 & 15 & 4 & 12 & 27 \\
PROACT II & IA pro-UK & 25 & 10 & - & 7 & 25 \\
MERCI & Merci device & 27.7 & 7.8 & - & 2.8 & 43.5 \\
Multi MERCI & Merci device & 30.5 & 9.8 & - & 0 & 34 \\
Penumbra & Penumbra device & 16.8 & 11.2 & - & - & 32.8 \\
MELT & IA UK & - & 9 & - & - & 5.3 \\
IMSI & IV tPA + IA tPA & 47.7 & 6.3 & - & - & 16 \\
IMS II & IV tPA + IA tPA + Ekos & - & 9.9 & - & - & 16 \\
EMS Bridging Trial & IV tPA + IA tPA & - & 12 & - & - & 45 \\
Total, mean \pm SD & All the above except NINDS & $29.1 \pm 10.2$ & $10.1 \pm 2.4$ & 4 & $7.2 \pm 4.6$ & $27.1 \pm 13.2$
\end{tabular}

Abbreviations: $\mathrm{AICH}=$ asymptomatic intracerebral hemorrhage; $\mathrm{ARF}=$ acute renal failure; $\mathrm{EMS}=$ Emergency Management of Stroke; IA = intra-arterial; IMS = Interventional Management of Stroke; MELT = Middle Cerebral Artery Embolism Local Fibrinolytic Intervention Trial; MERCI = Mechanical Embolus Removal in Cerebral Ischemia; NINDS = National Institute of Neurological Disorders and Stroke; PROACT = Prolyse in Acute Cerebral Thromboembolism; pro-UK = prourokinase; $\mathrm{sICH}=$ symptomatic intracerebral hemorrhage; $\mathrm{tPA}=$ tissue plasminogen activator.

Systemic hemorrhagic complications include access site hematoma, gastrointestinal hemorrhage, urinary tract hemorrhage, and retroperitoneal hemorrhage. Intracerebral hemorrhage (ICH) represents the most concerning complication and is usually associated with the use of thrombolytics ${ }^{6}$ or perforation of an artery wall induced by catheter and guidewire manipulations. Cardiac complications include arrhythmia, hypotension, and myocardial infarction. Other complications include allergic reaction to contrast media, acute renal failure, and catheter- and guidewire-related complications such as perforation, embolization, dissection, and formation of pseudoaneurysm. Placement of a stent could result in vasospasm and acute stent thrombosis. Certain retrieval devices, especially the early-generation Concentric thrombus retriever, have been known to fracture in up to $8 \%$ of cases. ${ }^{7}$ Using balloon angioplasty may result in balloon rupture, perforation, and vasospasm (table 2).

COMPLICATION AVOIDANCE AND PATIENT SELECTION CRITERIA Because of the fast progression of neuronal death in large-vessel occlusions, patient selection with regard to time from symptom onset to treatment represents a very important factor in improving the outcome and decreasing complication rates. The guidelines from the NINDS IV tPA study initially limited the treatment to patients who presented within 3 hours, and recently the benefit of IV tPA was also demonstrated in the 4.5-hour window in the European Cooperative Acute Stroke Study III trial. ${ }^{8}$ The Prolyse in Acute Cerebral Thromboembolism (PROACT) II trial extended the time to 6 hours, ${ }^{6}$ and the Mechanical Embolus Re- moval in Cerebral Ischemia (MERCI) trial extended the treatment window to 8 hours. ${ }^{2,7}$ The treatment window for basilar artery occlusion and thrombosis has been extended to 48 hours, as successful recanalization and improvement in outcome have been reported. ${ }^{9-10}$ Because of the high risk of complications with endovascular therapy, intervention should be reserved for patients who present with severe neurologic deficit (high NIH Stroke Scale score ${ }^{11}$ ), who are more likely to have large-artery occlusion ${ }^{9}$ and less likely to recanalize with IV tPA alone. In this group of patients, the benefit of intervention might outweigh the risks.

Advanced imaging techniques such as CT, CT perfusion, or MRI may improve the patient selection process. CT is the most readily available mode and allows rapid differentiation between ischemic and hemorrhagic infarcts. Early and large ischemic changes on CT correlate with poor outcome ${ }^{12}$ and increase the risk for hemorrhagic complication with endovascular therapy. ${ }^{13}$ Brain CT angiography can be helpful to confirm and localize a large-artery occlusion. CT perfusion identifies the area of hypoperfusion and might help to identify the ischemic core from the ischemic penumbra and therefore identify potentially salvageable tissue. ${ }^{14}$

Selecting patients on the basis of brain pathophysiologic analysis rather than strict time criteria was the premise behind the use of diffusion- and perfusionweighted imaging in multiple trials evaluating imageguided patient selection for interventional AIS therapy. ${ }^{15-16}$ The ongoing STroke, imAging, pRe- 
Table 2 List of the common complications associated with endovascular therapy for acute ischemic stroke ${ }^{a}$

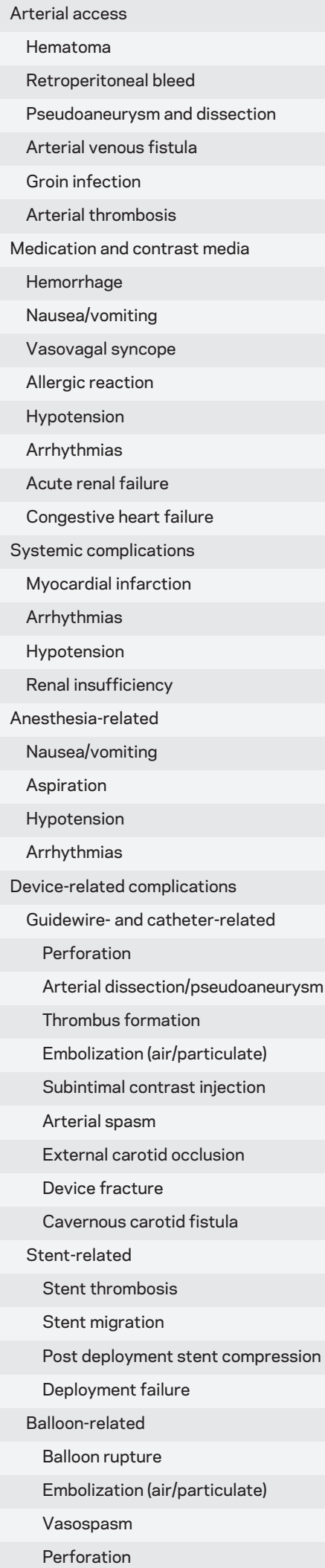

a The order in the table does not reflect the order of frequency. vention, and Treatment (START) and MR and Recanalization of Stroke Clots Using Embolectomy (MR RESCUE) trials are evaluating the application of advance imaging in endovascular therapy for AIS.

Experience with endovascular therapy for AIS over the past decade also showed that device selection might be important with regard to the site of arterial occlusion. Selecting the appropriate device will improve revascularization and decrease complications. For example, the Concentric thrombus retriever may be more useful for proximal middle cerebral artery occlusion and carotid T lesions, whereas the Penumbra catheter system (Penumbra, Inc., Alameda, CA) and IA tPA maybe more useful for distal lesions. ${ }^{17}$

\section{COMPLICATION RECOGNITION AND MANAGEMENT}

It is important to adequately report the risks of endovascular therapy to the patient and family before the intervention, given the high risk of complications. Early recognition once a complication occurs is crucial to significantly affect the outcome; therefore, the neurointerventionalist should be familiar with these complications and their management.

The newest-generation angiography suites are capable of topographic acquisition. This will make CT scanning of the head possible while the patient is still on the angiographic table. Such images in the future will aid in the immediate detection of possible complications. Here we discuss some of the most common complications associated with AIS endovascular therapy, with suggestions for management approaches.

Intracerebral hemorrhage. Because ICH significantly increases patient morbidity and mortality, ${ }^{18} \mathrm{ICH}$ is the most feared complication of AIS endovascular therapy. ICH most likely occurs secondary to reperfusing tissue that has already infarcted. ICH could also be secondary to direct perforation of a vessel by a catheter, microwire, or device. The effect of ICH can be severe, particularly if thrombolytic or antithrombotic agents were used. A large basal ganglia hemorrhage can be recognized by compression of the middle cerebral or anterior cerebral artery complex on angiography. Wire or device perforation can be recognized by contrast extravasation.

There are a few strategies for managing iatrogenic ICH. The first step is to recognize on fluoroscopy that a perforation has occurred, for example, if the wire, microcatheter, or retrieval device takes on a course outside the expected confines of the artery. It is then very important to resist the temptation to withdraw the device in question, because it may be creating a seal within the perforated site. In 1 case of AIS intervention, the authors left a microcatheter in situ because it was shown to provide a seal at the site 
of perforation. ${ }^{19}$ Evaluation for contrast extravasation via the guide catheter is important. If this is negative, then a microcatheter run could be performed if the microcatheter is suspected of being the cause of perforation, to verify its intravascular or extravascular location. Once perforation is confirmed, any ongoing thrombolytic, antithrombotic, or antiplatelet medication should be stopped immediately, and coagulopathy should be reversed with appropriate agents (i.e., factor VII or VIII, platelet infusion, protamine sulfate for heparin, cryoprecipitate for $\mathrm{PPA}$ ).

Temporary balloon occlusion at the site of perforation might be considered to prevent further bleeding. Sacrificing a vessel in order to stop bleeding may be necessary to save the patient's life. A CT scan of the head should be obtained immediately to evaluate the size and location of the bleed. It is very important to differentiate between ICH and extravasation of contrast, which may occur because of the impaired blood-brain barrier.

MRI is particularly useful in differentiating between a hemorrhage and extravasation of contrast from blood-brain barrier disruption. In fact, as blood ages, hemoglobin changes through several forms such as oxyhemoglobin, deoxyhemoglobin, and methemoglobin before the red blood cells are broken down into ferritin and hemosiderin. The susceptibility artifact generated by the different hemoglobin degradation products is detected very well by MRI. Conversely, iodinated contrast does not cause susceptibility artifacts and therefore is not detected by the MRI. ${ }^{20}$

Patients with a suspected or confirmed complication of ICH should be sent to the neurocritical care unit. Blood pressure management is crucial in managing ICH. With the lack of definite data, we recommend keeping systolic blood pressure between 120 and $160 \mathrm{~mm} \mathrm{Hg}$ and diastolic blood pressure less than $90 \mathrm{~mm} \mathrm{Hg}$.

Prevention, early recognition, and treatment for vasospasm should be considered with subarachnoid hemorrhage. Prophylactic antiepileptic therapy may be considered. Ventriculostomy placement may be indicated with hydrocephalus on CT scan, suspected elevated intracranial pressures, or when intracranial pressure needs to be monitored and controlled. Early surgical decompression and prevention of cerebral edema may be useful in particular for ICH in the posterior fossa; this conclusion is derived from the published guideline on spontaneous $\mathrm{ICH} .{ }^{21}$

Arterial dissection. Endovascular intervention can cause iatrogenic intracranial and extracranial dissection. In a large review of more than 3,000 patients, the rate of iatrogenic dissection was $0.4 \% .{ }^{22} \mathrm{Al}$ though iatrogenic dissection may be benign in many cases, it can also result in significant neurologic deficits. ${ }^{23}$ Angioplasty or stenting could be considered for a flow-limiting dissection or to access a distal clot through a dissection. ${ }^{24}$ If the dissection does not compromise the blood flow or the patient's neurologic status, then medical treatment with antithrombotic or antiplatelet agents can be considered.

In situ thrombosis. In situ thrombosis and clot formation associated with endovascular therapy are significant complications and account for a large proportion of worsening neurologic status associated with endovascular interventions. Clot formation and thrombosis are likely related to the induction of the coagulation process and platelet activation, as well as the limited blood flow induced by IA devices in areas where blood flow may already be compromised by the acute stroke. A continuous infusion of heparinized normal saline, which flushes out the system, is important to prevent thrombosis. To treat in situ thrombosis, we suggest giving heparin boluses to optimize anticoagulation. Adding a small dose of a glycoprotein IIb/IIIa inhibitor might be considered. ${ }^{25}$ If these treatments fail, then mechanical removal of thrombus may be necessary.

Air emboli. Although air emboli during neuroendovascular procedures are rarely symptomatic, they were reported to account for almost $0.08 \%$ of significant neurologic deficits in a large review of nearly 4,500 patients. ${ }^{26}$ The source of the air emboli might be the arterial flushed line or suddenly applied negative pressure causing air to enter the catheter. The best approach to avoid air emboli is to meticulously and gently prep and flush the catheters and the devices to remove the air bubbles, and to minimize the number of microcatheter runs. If air emboli result in symptomatic deficits, then use of $100 \%$ oxygen or a hyperbaric chamber to treat those complications may be considered. ${ }^{27}$

Distal emboli. The risk of distal migration of a clot is a concern during manipulation to retrieve a clot. The clot may migrate more distally to another single branch or might break into small clots and cause multiple distal emboli in multiple smaller branches. The interventionalist at this time might consider changing the treatment strategy, depending on the new locations of the clots. If the clot is proximal, recanalization can be achieved with SNARE wire manipulation, or possibly with the Merci thrombus retriever (Concentric Medical, Inc.) or the Penumbra catheter system. If the clot is more distal or in multiple branches, thrombolytics may be considered.

Vasospasm. Catheter and wire manipulation can result in arterial vasospasm. Transluminal angio- 
plasty and IA papaverine ${ }^{28}$ administration have been the mainstay of endovascular vasospasm treatment. Calcium channel blockers such as nicardipine and verapamil have also been shown to improve the vasospasm. ${ }^{29-30}$

Carotid cavernous fistula. Carotid cavernous fistula usually results from a direct wire perforation during a revascularization manipulation; rarely, it results from an angioplasty. ${ }^{31}$ Multiple strategies have been used to treat the fistula, including stent placement ${ }^{32}$ or a stent-assisted coil occlusion of the fistula. ${ }^{33}$ Onyx (vinyl alcohol copolymer) embolization into the cavernous sinus has been prescribed, either with a direct transorbital access ${ }^{34}$ or via a transvenous access. $^{35}$ Onyx embolization can also be achieved intra-arterially into the cavernous sinus through the perforation if the interventionalist maintains an access after the perforation (figure).

\section{Figure Carotid cavernous fistula (CCF) developed during endovascular therapy for left middle cerebral artery (MCA) occlusion}
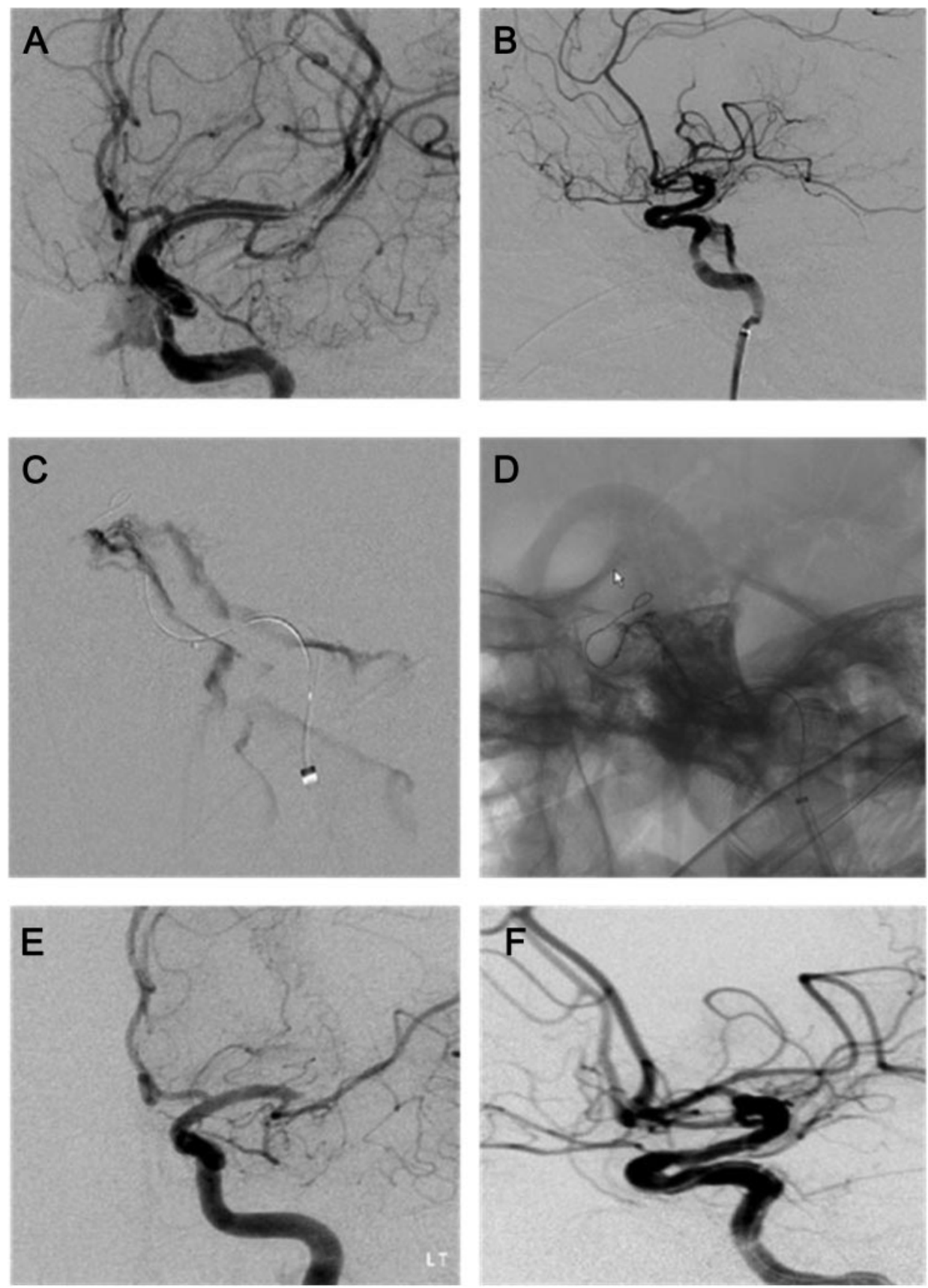

(A) Anterior-posterior view shows the left CCF; (B) lateral view shows the left CCF; (C) microcatheter injection confirms the formation of CCF; (D) Onyx (vinyl alcohol copolymer) injection via the microcatheter; (E) anterior-posterior view shows complete occlusion of the left CCF; (F) lateral view shows complete occlusion of the left CCF. 
DISCUSSION Over the past decade, endovascular therapy has emerged as a promising therapeutic approach for select patients with AIS. However, the morbidity, mortality, and complication rates in IA recanalization trials are higher than in the IV tPA trials. Complication avoidance and patient selection are very important factors in decreasing the rate of complications. Early recognition and appropriate management are crucial to significantly improve the outcome for patients who undergo endovascular therapy for AIS.

\section{AUTHOR CONTRIBUTIONS}

Dr. Darkhabani: drafting/revising the manuscript, study concept or design, acquisition of data. Dr. Nguyen and Dr. Lazzaro: drafting/revising the manuscript. Dr. Zaidat: drafting/revising the manuscript, study concept or design, acquisition of data, study supervision. Dr. Lynch: drafting/ revising the manuscript, study concept or design, acquisition of data, contributing reagents, study supervision. Dr. Fitzsimmons: study concept or design, acquisition of data, contributing reagents, study supervision. Dr. Linfante: drafting/revising the manuscript, study concept or design, study supervision.

\section{DISCLOSURE}

Drs. Darkhabani, Lazzaro, Lynch, and Fitzsimmons report no disclosures. Dr. Nguyen serves as Associate Editor of Frontiers of Vascular and Interventional Neurology and Editor of SVIN Newsletter The Core; performs intra-arterial stroke procedures; and serves as a consultant for Penumbra. Dr. Zaidat serves on the Scientific Advisory Board for Talecris; served on the adjudication committee for Stryker; received speaker honoraria from Stryker; served on the editorial board of Frontiers in Neurology (Endovascular \& Interventional Neurology Section); serves as Editor of The Journal of Neurointerventional Surgery, and serves as Associate Editor and is a member of the Editorial Board of Journal of Stroke \& Cerebrovascular Diseases; served as a consultant for Stryker Neurovascular, Codman Neurovascular, and Microvention Inc.; and has received research support from Society of Vascular \& Interventional Neurology (SVIN) for this educational activity. Dr. Linfante served as a consultant for Codman Neurovascular and Stryker; holds stock options in Surpass Limited; serves on the Scientific Advisory Board for Codman Neurovascular; serves on the editorial boards for Stroke and Journal of Neurointerventional Surgery; and serves on the speakers bureau for Codman. Go to Neurology.org for full disclosures.

Received July 9, 2011. Accepted in final form December 8, 2011.

\section{REFERENCES}

1. Report of the WHO Task Force on Stroke and other Cerebrovascular Disorders: recommendations on stroke prevention, diagnosis, and therapy. Stroke 1989;20:14071431.

2. Smith WS, Sung G, Saver J, et al., for the Multi MERCI Investigators. Mechanical thrombectomy for acute ischemic stroke: final results of the Multi-Merci trial. Stroke 2008;39:1205-1212.

3. Rha J-H, Saver JL. The impact of recanalization on ischemic stroke outcome. Stroke 2007;38:967-973.

4. The National Institute of Neurological Disorders and Stroke rt-PA Stroke Study Group. Tissue plasminogen activator for acute ischemic stroke. N Engl J Med 1995;333: $1581-1587$.

5. US Food and Drug Administration. Summary basis of approval. Genentech, applicant: Activase for acute ischemic stroke. New Drug Application PLA96-0350.
6. Furlan AJ, Higashida R, Wechsler L, et al. Intra-arterial prourokinase for acute ischemic stroke: the PROACT II Study: a randomized controlled trial. JAMA 1999;282: 2003-2011.

7. Smith WS, Sung G, Starkman S, et al.; MERCI Trial Investigators. Safety and efficacy of mechanical embolectomy in acute ischemic stroke: results of the MERCI trial. Stroke 2005;36:1432-1438.

8. Hacke W, Kaste M, Bluhmki E, et al. Thrombolysis with alteplase 3 to 4.5 hours after acute ischemic stroke. N Engl J Med 2008;359:1317-1329.

9. Berg-Dammer E, Felber SR, Henkes H, Nahser HC, Kuhne D. Long-term outcome after local intra-arterial fibrinolysis of basilar artery thrombosis. Cerebrovasc Dis 2000;10:183-188.

10. Lindsberg PJ, Soinne L, Tatlisumak T, et al. Long-term outcome after intravenous thrombolysis of basilar artery occlusion. JAMA 2004;292:1862-1866.

11. Fischer U, Arnold M, Nedeltchev K, et al. NIHSS score and arteriographic findings in acute ischemic stroke. Stroke 2005;36:2121-2125.

12. Roberts HC, Dillon WP, Furlan AJ, et al. Computed tomography findings in patients undergoing intra-arterial thrombolysis: for acute ischemic stroke due to middle cerebral artery occlusion: results from the PROACT II trial. Stroke 2005;33:1557-1565.

13. Vora N.A, Gupta R, Thomas AJ, et al. Factors predicting hemorrhagic complications after multimodal reperfusion therapy for acute ischemic stroke. AJNR Am J Neuroradiol 2007;28:1391-1394.

14. Wintermark M, Flanders AE, Velthuis B, et al. Perfusion-CT assessment of infarct core and penumbra: receiver operating characteristic curve analysis in $130 \mathrm{pa}-$ tients suspected of acute hemispheric stroke. Stroke 2006; 37:979-985.

15. Hacke W, Albers G, Al-Rawi Y, et al. The Desmoteplase in Acute Ischemic Stroke trial (DIAS): a phase II MRI-based 9-hour window acute stroke thrombolysis trial with intravenous desmoteplase. Stroke 2005;36:66-73.

16. Ribo M, Molina CA, Rovira A, et al. Safety and efficacy of intravenous tissue plasminogen activator stroke treatment in the 3- to 6-hour window using multimodal transcranial Doppler/MRI selection protocol. Stroke 2005;36:602606.

17. The penumbra pivotal stroke trial: safety and effectiveness of a new generation of mechanical devices for clot removal in intracranial large vessel occlusive disease. Stroke 2009; 40:2761-2768.

18. Becker KJ, Monsein LH, Ulatowski J, Mirski M, Williams $\mathrm{M}$, Hanley DF. Intraarterial thrombolysis in vertebrobasilar occlusion. AJNR Am J Neuroradiol 1996;17:255-562.

19. Nguyen TN, Lanthier S, Roy D. Iatrogenic arterial perforation during acute stroke interventions. AJNR Am J Neuroradiol 2008;29:974-975.

20. Greer DM, Koroshetz WJ, Cullen S, Gonzalez RG, Lev $\mathrm{MH}$. Magnetic resonance imaging improves detection of intracerebral hemorrhage over computed tomography after intra-arterial thrombolysis. Stroke 2004;35:491-495.

21. Morgenstern LB, Hemphill JC 3rd, Anderson C, et al. Guidelines for the management of spontaneous intracerebral hemorrhage: a guideline for healthcare professionals from the American Heart Association/American Stroke Association: American Heart Association Stroke Council 
and Council on Cardiovascular Nursing SO. Stroke 2010; 41:2108.

22. Cloft HJ, Jensen ME, Kallmes DF, et al. Arterial dissections complicating cerebral angiography and cerebrovascular intervention. AJNR Am J Neuroradiol 2000; 21:541-545.

23. Hosoya T, Watanabe N, Yamaguchi K, et al. Intracranial vertebral artery dissection in Wallenberg syndrome. AJNR Am J Neuroradiol 1994;15:1161-1165.

24. Dorros G, Cohn JM, Palmer LE. Stent deployment resolves a petrous carotid artery angioplasty dissection. AJNR Am J Neuroradiol 1998;19:392-394.

25. Cloft HJ, Samuels OB, Tong FC, Dion JE. Use of abciximab for mediation of thromboembolic complications of endovascular therapy. AJNR Am J Neuroradiol 2001;22: 1764-1767.

26. Gupta R, Vora N, Thomas A, et al. Symptomatic cerebral air embolism during neuro-angiographic procedures: incidence and problem avoidance. Neurocrit Care 2007;7: 241-246.

27. Murphy BP, Harford FJ, Cramer FS. Cerebral air embolism resulting from invasive medical procedures: treatment with hyperbaric oxygen. Ann Surg 1985;201:242-245.

28. Milburn JM, Moran CJ, Cross DT III, et al. Increase in diameters of vasospastic intracranial vessels by intraarterial papaverine administration. J Neurosurg 1998;88:38-42.
29. Feng L, Fitzsimmons BF, Young WL, et al. Intra-arterially administered verapamil as adjunct therapy for cerebral vasospasm: safety and 2-year experience. AJNR Am J Neuroradiol 2002;23:1284-1290.

30. Badjatia N, Topcuoglu MA, Pryor JC, et al. Preliminary experience with intra-arterial nicardipine as a treatment for cerebral vasospasm. AJNR Am J Neuroradiol 2004;25: $819-826$.

31. Linfante I, Del Gado-Meros R, Gounis M, Andreone V, Hendricks L, Wakhloo AK. Hemodynamic and angiographic effect of high concentration of intra-arterial nicardipine in cerebral vasospasm. Neurosurgery 2008;63:1080-1087.

32. Kim SH, Qureshi AI, Boulos AS, et al. Intracranial stent placement for the treatment of a carotid-cavernous fistula associated with intracranial angioplasty: case report. J Neurosurg 2003;98:1116-1119.

33. Morón FE, Klucznik RP, Mawad ME, Strother CM. Endovascular treatment of high-flow carotid cavernous fistulas by stent-assisted coil placement. AJNR Am J Neuroradiol 2005;26:1399-1404.

34. Elhammady MS, Peterson EC, Aziz-Sultan MA. Onyx embolization of a carotid cavernous fistula via direct transorbital puncture. J Neurosurg 2011;114:129-132.

35. Bhatia KD, Wang L, Parkinson RJ, Wenderoth JD. Successful treatment of six cases of indirect carotid-cavernous fistula with ethylene vinyl alcohol copolymer (Onyx) transvenous embolization. J Neuroophthalmol 2009;29:3-8. 


\section{Neurology}

\section{Complications of endovascular therapy for acute ischemic stroke and proposed management approach}

Ziad Darkhabani, Thanh Nguyen, Marc A. Lazzaro, et al. Neurology 2012;79;S192-S198

DOI 10.1212/WNL.0b013e31826958e3

This information is current as of September 24, 2012

\section{Updated Information \&} Services

References

Subspecialty Collections

Permissions \& Licensing

Reprints including high resolution figures, can be found at: http://n.neurology.org/content/79/13_Supplement_1/S192.full

This article cites 34 articles, 15 of which you can access for free at: http://n.neurology.org/content/79/13_Supplement_1/S192.full\#ref-list1

This article, along with others on similar topics, appears in the following collection(s):

\section{All Cerebrovascular disease/Stroke}

http://n.neurology.org/cgi/collection/all_cerebrovascular_disease_strok e

Information about reproducing this article in parts (figures,tables) or in its entirety can be found online at:

http://www.neurology.org/about/about_the_journal\#permissions

Information about ordering reprints can be found online:

http://n.neurology.org/subscribers/advertise

Neurology ${ }^{\circledR}$ is the official journal of the American Academy of Neurology. Published continuously since 1951, it is now a weekly with 48 issues per year. Copyright Copyright $@ 2012$ by AAN Enterprises, Inc.. All rights reserved. Print ISSN: 0028-3878. Online ISSN: 1526-632X.

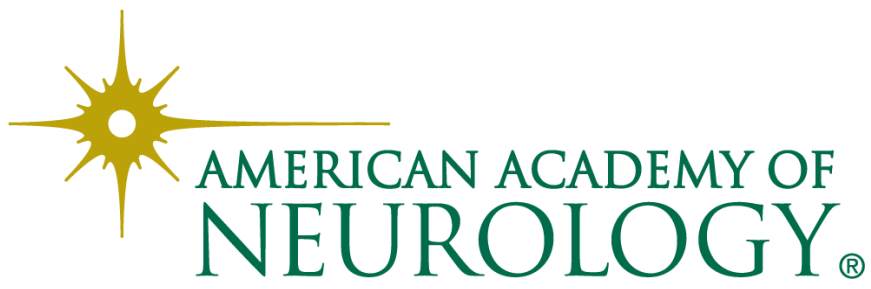

